\title{
COMPREHENSIVE SPECTROSCOPIC DATA TABULATIONS AND PROGRESS IN THE COMPILATION OF ATOMIC TRANSITION PROBABILITIES
}

\author{
W.L. WIESE \\ National Institute of Standards and Technology Gaithersburg, Maryland \\ 20899, U.S.A.
}

\begin{abstract}
The critical data compilation work as well as the bibliographical efforts of two data centers on atomic spectroscopy at the National Institute of Standards and Technology (formerly the National Bureau of Standards) are briefly reviewed. A complete listing of all current compilations on wavelengths, energy levels and transition probabilities is given. A recently completed large tabulation of atomic transition probabilities for the Fe-group elements comprising about 18000 lines is discussed in some detail, and several data comparisons are presented in order to provide an impression of the current status of these atomic data.
\end{abstract}

\section{A. Introduction}

Atomic spectral lines, originating from discrete transitions of electrons in atoms and ions, are principally characterized by their wavelengths and associated spectroscopic notation; the energies of the upper and lower atomic levels involved in the transition; the atomic oscillator strength (or transition probability or line strength); and line shape parameters. These quantities are critically evaluated and compiled at two data centers at the National Institute of Standards and Technology (NIST). The centers are (a) the Data Center on Atomic Energy Levels, which also compiles and critically evaluates wavelength data, and (b) the Data Center on Atomic Transition Probabilities where also the literature references on Atomic Line Shapes are collected, along with literature references on transition probabilities. The two data centers at NIST operate with a very small work force, consisting of one senior physicist or equivalent and one junior physicist.

\section{B. Bibliographical Data Center Work}

One of the basic functions of the data centers is to collect all relevant literature and to maintain bibliographical databases. As of the end of 1989 , the bibliographic database on atomic energy levels contained about 12,000 papers, with the large majority of the references published in several bibliographies ${ }^{1,2}$. The bibliographic database of the Data Center on Atomic Transition Probabilities contain about 1,500 papers and is still in the process of being built up.

About 4000 older papers are also part of the transition probability data files and are included in earlier bibliographies ${ }^{3}$. From this material in the databases and the material contained in earlier published bibliographies, an overview of the availability of the spectroscopic data is readily obtained. As an example, the situation on the availability of atomic transition probabilities is presented in Figure 1, in which the chemical elenents are plotted in order of increasing atomic number vs. stage of ionization. Those spectra for which an adequate number of reliable data are available (uncertainties estimated to be less than \pm 50 \%) are shown as black squares. Those spectra for which relatively few data exist are denoted by a crosshatched square, while all other spectra have been left blank, indicating that either no data or few data are available. The graph shows that the data situation is only satisfactory for light elements up to about atomic number $Z=28$ (nickel). For all heavier elements, data are only available for the neutral and singly ionized atoms, as well as for a number of highly-stripped ions which are isoelectronic with very light elements and thus have the same relatively simple atomic structure. These latter data. which have been calculated with sophisticated atomic structure programs for whole isoelectronic sequences, show up as diagonal structures, starting with the light neutral atoms and going to the highest stages of ionization listed. 
Generally, the material on atomic transition probabilities covers fewer spectra and fewer lines than the material on wavelengths and energy levels. It should be noted that a similar graph showing the availability of atomic energy levels may be found in reference 4.

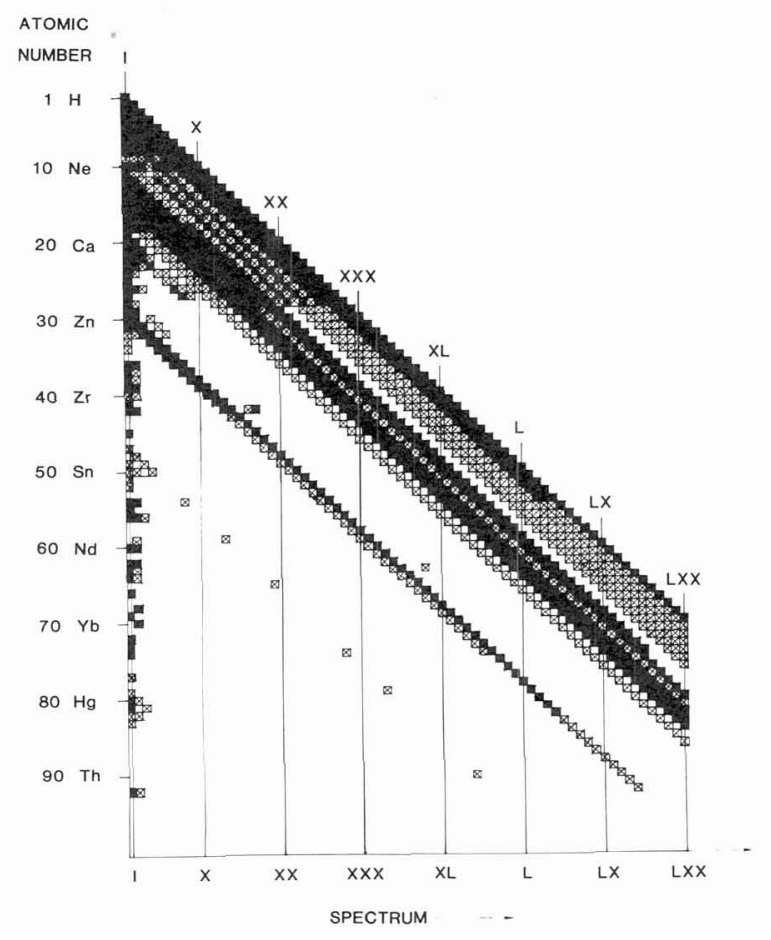

Fig. 1. Availability of reliable atomic transition probability data for the spectra of all natural elements. Roman numeral I denotes the spectrum of neutral atoms, II the spectrum of singly ionized atoms, etc. Isoelectronic sequences appear as diagonal lines. Black squares indicate that the data situation is satisfactory; cross-hatched squares indicate that the existing data are quite sketchy, blank squares indicate that no or very few data are available.

\section{Major Data Center Tabulations}

The most important function of the NIST data centers is their critical evaluation and compilation work. Over the last 50 years a number of evaluated data tables have been published which have come into wide use as standard tables of spectroscopic reference data. An overview of reference data works from NIST as well as elsewhere is given in Table 1 , which lists the most current compilations for wavelengths, energy levels and transition probabilities for the various chemical elements in order of increasing atomic number. It is seen that some of the reference tables are rather old and need to be updated, which is fully recognized at NIST.

\section{Critical Assessment of Transition Probability Data}

As noted above, the most important function of the data centers is the critical assessment and compilation of spectroscopic data. The assessment problems are especially critical for atomic transition probabilities, for which the uncertainties are large-typically in the 25-508 range--because these quantities are difficult to determine. Therefore, it is important to discuss the data assessment procedure at NIST. Actually, realistic uncertainty estimates are possible only for the measured data, while for the complex theoretical atomic structure approximations quantitative error assessments are usually not feasible. 
Table 1. References for the Most Recent Data Tables on Wavelengths, Energy Levels and Transition Probabilities

\begin{tabular}{|c|c|c|c|c|c|c|c|c|c|}
\hline \multirow[t]{2}{*}{2} & \multirow{2}{*}{$\begin{array}{l}\text { Element } \\
\text { Symbol }\end{array}$} & \multicolumn{3}{|c|}{ Data Tabulations on } & \multirow[t]{2}{*}{$\mathrm{Z}$} & \multirow{2}{*}{$\begin{array}{l}\text { Element } \\
\text { Symbol }\end{array}$} & \multicolumn{3}{|c|}{ Data Tabulations on } \\
\hline & & $\begin{array}{l}\text { Wave - } \\
\text { Lengths }\end{array}$ & $\begin{array}{l}\text { Energy } \\
\text { Levels }\end{array}$ & $\begin{array}{c}\text { Transition } \\
\text { Probabilities }\end{array}$ & & & $\begin{array}{l}\text { Wave - } \\
\text { Lengths }\end{array}$ & $\begin{array}{l}\text { Energy } \\
\text { Levels }\end{array}$ & $\begin{array}{l}\text { Transition } \\
\text { Probabilities }\end{array}$ \\
\hline 1 & $\mathrm{H}, \mathrm{D}, \mathrm{T}$ & 5 & 5 & 6 & 19 & $K$ & $7,8,9$ & 23 & 17 \\
\hline 2 & $\mathrm{He}$ & $7,8,9$ & 10,11 & 6 & 20 & $\mathrm{Ca}$ & $7,8,9$ & 23 & 17 \\
\hline 3 & $\mathrm{Li}$ & $7,8,9$ & 12 & 6 & 21 & Sc & 24 & 23 & 25 \\
\hline 4 & $\mathrm{Be}$ & 7,8 & 12 & 6 & 22 & $\mathrm{Ti}$ & $7,8,9$ & 23 & 25 \\
\hline 5 & $B$ & 7,8 & 12 & 6 & 23 & $\mathrm{~V}$ & 7,8 & 23 & 25 \\
\hline 6 & $\mathrm{C}$ & $7,8,9,13$ & 13 & 6 & 24 & $\mathrm{Cr}$ & 7,8 & 23 & 25 \\
\hline 7 & $\mathrm{~N}$ & $7,8,9,14$ & 14 & 6 & 25 & $\mathrm{Mn}$ & 7,8 & 23 & 25 \\
\hline 8 & 0 & $7,8,9,15$ & 15 & 6 & 26 & $\mathrm{Fe}$ & $7,8,9$ & 23 & 26 \\
\hline 9 & $F$ & $7,8,9$ & 12 & 6 & 27 & Co & 7,8 & 23 & 26 \\
\hline 10 & $\mathrm{Ne}$ & $7,8,9$ & 12 & 6 & 28 & $\mathrm{Ni}$ & 7,8 & 23 & 26 \\
\hline 11 & $\mathrm{Na}$ & $7,8,9$ & 16 & 17 & 29 & $\mathrm{Cu}$ & $7,8,9$ & 27 & 28 \\
\hline 12 & $\mathrm{Mg}$ & $7,8,9$ & 18 & 17 & 30 & $\mathrm{Zn}$ & 7,8 & 12 & 28 \\
\hline 13 & Al & $7,8,9$ & 19 & 17 & 31 & $\mathrm{Ga}$ & 7,8 & 12 & 28 \\
\hline 14 & Si & $7,8,9$ & 20 & 17 & 32 & $\mathrm{Ge}$ & 7,8 & 12 & 28 \\
\hline 15 & $\mathrm{P}$ & 7,8 & 21 & 17 & 33 & As & 7,8 & 12 & 28 \\
\hline 16 & $\mathrm{~S}$ & 7,8 & 22 & 17 & 34 & $\mathrm{Se}$ & 7,8 & 12 & 28 \\
\hline 17 & $\mathrm{Cl}$ & $7,8,9$ & 12 & 17 & 35 & $\mathrm{Br}$ & 7,8 & 12 & 28 \\
\hline 18 & Ar & 7.8 .9 & 12 & 17 & 36 & $\mathrm{Kr}$ & 7.8 .9 & 12 & 28 \\
\hline
\end{tabular}

For elements heaviex than $2=36$ :

Wavelength Data:

Energy Level Data:

Transition Probability Data:
Ref. 8

Ref. 12 (Vols. II and III)

Ref. 63, Molybdenum

Ref. 64, Rare Earths, La-Lu ( $Z=57-71)$

Ref. 28 .

We have developed the following general procedure for judging experimental material, to which we subject all data:

1. We take into account our general evaluation of the capabilities and shortcomings of the specific technique applied by the authors.

2. We look for consideration by the authors of the "critical features" (see below) in each technique.

3. We check the agreement or disagreement with other reliable data.

4. We take into account the authors' estimate of their uncertainties.

5. We check the degree of fit of the data into systematic trends.

The most important criterion is item 2, i,e., the specific "critical factors" for each method that must be taken into account by the authors in order to obtain reliable results. These critical factors have been discussed in the introductory discussions of the NIST data tables in considerable detail, especially in Refs. 6 and 17 . For example, in the determination of lifetimes of excited atomic levels the following three critical factors are of key importance:

(a) absence of radiation trapping,

(b) absence of collisional de-and repopulation of the atomic level,

(c) absence of repopulation of the level by cascading.

Radiation trapping and collisional effects both change the lifetime, and must be checked and eliminated by varying the densicy in the target chamber, and by extrapolating the results to zero density.

Furthermore, the excitation must either be completely selective with respect to the upper level of the transition in question or, if it is non-selective so that electron cascading from higher levels may occur, a reliable correction technique must be applied such as the ANDC technique. ${ }^{9}$ Fits to 2- or 3 - exponential decays are not adequate, as has been repeatedly shown in the literature ${ }^{30}$. 


\section{E. Comprehensive Tables for Atomic Transition Probabilities of the Iron-Group Elements}

By carrying out a systematic evaluation of all experimental and theoretical data with the 5-point procedure described above, two comprehensive data volumes covering the atomic transition probabilities for all spectra of the Fe-group elements have been recently completed and published 5,26 . About 18,000 transitions have been included.

Most data for the lower spectra are from experimental sources, while theoretical approaches have been the almost exclusive source of data for high stages of ionization. The typical accuracy of the data may be considered as only fair-to-adequate, with most lines estimated to be uncertain to either about \pm 258 , ("C" category) or \pm 508 (" $D$ " category). However, some of the neutral spectra as well as those for highly ionized atoms are in relatively good shape. In the following, we discuss some especially interesting cases, in order to provide an impression of the general quality and consistency of the compiled data.

1. The Spectrum of Neutral Iron: For this very important spectrum, reliable data were found for about 2,000 lines. These represent most of the lines of moderate and high strength in the ultraviolet and visible regions of the spectrum. Due to recent advanced experiments based on the absorption as well as the emission method, it is estimated that the oscillator strengths for about half of these lines are known to better than $\pm 25 \%$. It is important to recall that the emission and absorption experiments provide only relative data so that for the normalization to an absolute scale the absolute value for a key line must be accurately known. For neutral iron the resonance line at $3720 \dot{A}$ has been repeatedly determined with a variety of atomic lifetime techniques. As Table 2 shows, these lifetime data ${ }^{3-37}$ are in excellent agreement, providing a mean value with a standard deviation of only 0.38 , which serves as an excellent normalization point for this spectrum. For many lines, data are available from several emission ${ }^{38,41}$ and absorption experiments ${ }^{39,40}$ and may thus be compared for a check of their mutual consistency. Figures 2 and 3 represent two examples for these comparisons and show that for a large part of lines the emission and absorption studies are consistent within \pm 258 . In a few cases where larger discrepancies occurred these could be traced to specific circumstances for these lines only, as-for example--problems with radiometric standards at short wavelengths.

2. The Spectrum of Singly Ionized Iron: The spectra of singly ionized atoms often are represented by much fewer data in the NIST tabulations than the neutral atoms. This is because spectra of atomic ions are much more difficult to generate and investigate experimentally. On the other hand, for Fe-group elements the difference in complexity between the first and second spectra is usually small so that theoretical treatments are just as difficult for both spectra and very few reliable theoretical treatments exist. Fe II is one of the cases where some fairly accurate theoretical data are available, but otherwise it is typical in terms of the situation described above.

Table 2. Selected Lifetime and Oscillator Strength Data for the Fe I $z{ }^{5} F_{5}^{*}$ Resonance Level

\begin{tabular}{|c|c|c|}
\hline Reference & $\begin{array}{l}\text { Lifetime in } n s \\
\text { of the } z{ }^{5} \mathrm{~F}_{5}^{\circ} \\
\text { Level }\end{array}$ & $\begin{array}{c}\text { Oscillator Strength } \\
\text { of the } \\
3719.93 \dot{A} \text { Line }\end{array}$ \\
\hline $\begin{array}{l}\text { Wagner and otten } 31 \\
\text { Klose } 32 \\
\text { Hilborn and de Zafra } \\
\text { Brzozowski et al. }{ }^{34} \\
\text { Marek, Richter, and } \\
\text { Stahnke } \\
\text { Hannaford and Lowe } \\
\text { Bell and Tubbs }\end{array}$ & $\begin{array}{l}59.5 \pm 1.6 \\
61.5 \pm 0.4 \\
63.2 \pm 3.6 \\
60.5 \pm 1.5 \\
62.4 \pm 4.2 \\
61.0 \pm 1.0\end{array}$ & $\begin{array}{l}0.0425 \\
0.0413 \\
0.0400 \\
0.0418 \\
0.0405 \\
0.0414 \\
0.041 \pm 0.003\end{array}$ \\
\hline
\end{tabular}




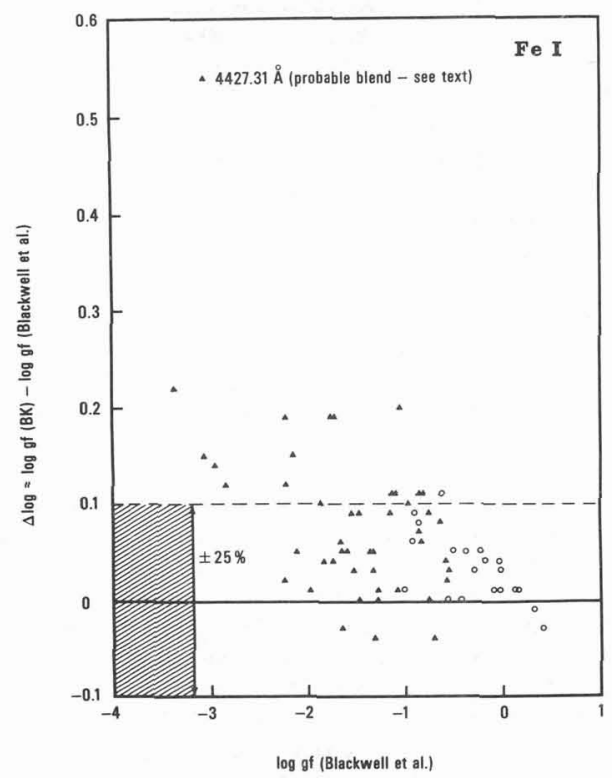

Fig. 2. Comparison of some oscillator strength (gf-value) data for Fe I lines. The emission work by Bridges and Kornblith ${ }^{38}$ is compared on a logarithmic scale with the absorption work by Blackwell et al. ${ }^{9}, 40$ Open circles are given for those lines for which Bridges and Kornblith estimate their data to be accurate within 108, while solid triangles indicate lines with uncertainties up to $25 \%$. Blackwell et al. estimate the uncertainties of their relative values to be less than $1 \%$. The two data sets are normalized to slightly different absolute scales, which contain additional uncertainties.

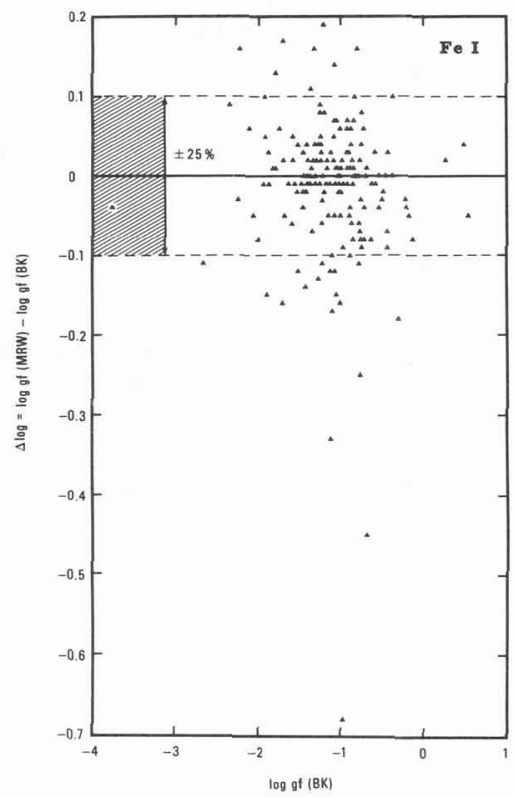

Fig. 3. Comparison of the results of two emission experiments by May et al.41 and Bridges and Kornblith ${ }^{3}$ for Fe I. Ratios of oscillator strengths or gf-values are given on a logarithmic scale. For a few transitions-all in the ultraviolet--strong disagreements are observed, which appear to be due to scattered light problems with the radiometric standard used by May et al. 
For Fe II, transition probabilities are available for only about one-third as many lines as for $\mathrm{Fe} I$ and the quality of the experimental data is significantly lower. The mix of experimental approaches has shifted and emission work now dominates. The principal experiment utilized for the NIST tables on Fe II is a wall-stabilized arc experiment by Moity ${ }^{2}$ which has yielded about two-thirds of the 646 listed lines. Moity's work is not as advanced as that of other recent wall-stabilized arc experiments. He used photographic detection and thus had to convert photographic plate densities into radiances by a photometric procedure, while nowadays most experimenters utilize photoelectric detection. His plasma diagnostics involves spectroscopic measurements of neutral-atom lines and is based on the assumption of full local thermodynamic equilibrium (LTE) for his source. He used the LTE model to relate Fe I populations, derived from lines with known transition probabilities, to Fe II excited state populations by the Saha equation,--a risky procedure for his experimental conditions. The data by Moity have therefore been judged very conservatively in the NIST tabulation and uncertainties of about $\pm 50 \%$ have been estimated, roughly twice his own error estimates (which are basically standard deviations).

The Fe II spectrum is one of the cases where the semi-empirical calculations by Kurucz ${ }^{43}$ have produced fairly accurate data. His results are very dependent on accurate input data on atomic energy levels and in the case of Fe II the recent work by Johansson ${ }^{4}$ provided a very complete, accurate set of such levels. Therefore, Kurucz's data were utilized for about $10 \%$ of the NIST tabulation--specifically for all lines of moderate strength for which no experimental data were available. The satisfactory agreement between Kurucz's results for stronger lines and the experimental results used in the NIST tabulation is readily seen from a graphical comparison of these data (Figure 4). Assuming uncertainties of $\pm 50 \%$ for Kurucz's data as well as using the uncertainty estimates given in the NIST tabulation for the various experiments (usually 25-50\%) we find mutual consistency for about $80 \%$ of the lines.

3. The Spectrum of Neutral Chromium: In addition to Fe I, this is one of the neutral spectra for which a good bit of recent experimental activity occurred. For some transitions, results are available from a considerable number of experiments. The example in Table 3 shows a comparison of several absorption and lifetime data ${ }^{45-51}$ for two Cr I multiplets. The lifetime techniques applied in this case utilized either the Hanle (levelcrossing) effect, or the phase-shift technique, or the delayed coincidence method with selective laser excitation. The table clearly shows the excellent agreement among the various approaches, warranting an uncertainty estimate of only $\pm 10 \%$.

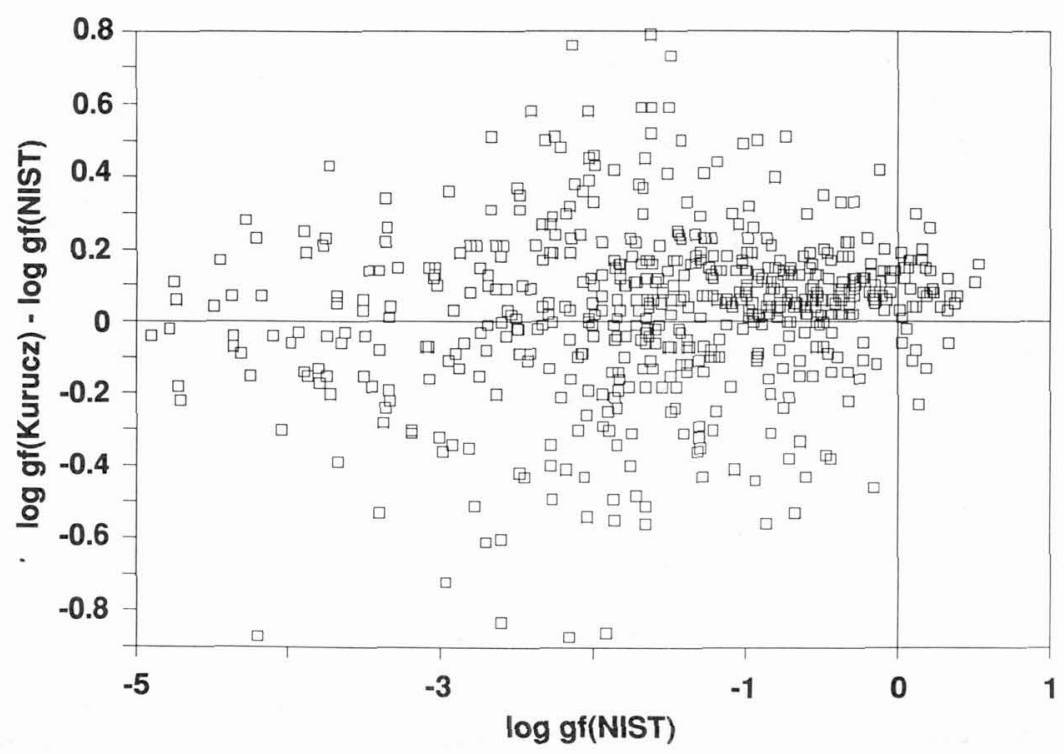

Fig. 4. Comparison of the results of the semiempirical calculations by Kurucz ${ }^{43}$ with those experimental results that were selected for the recent NIST tabulations on Fe II. ${ }^{26}$ Compared are the oscillator strengths (gf-values) on a logarithmic scale. 
Table 3. Comparison of Absorption and Lifetime Data for Two Cr I Multiplets

\begin{tabular}{|c|c|c|c|c|c|c|c|c|}
\hline Multiplet & $\lambda(\AA)$ & $\begin{array}{c}\mathbf{f}_{i k} \\
(\text { Bieni- } \\
\text { ewski }\end{array}$ & $\begin{array}{l}f_{i k}{ }^{a} \\
(\text { Becker } \\
\left.\text { et al. } .^{46}\right)^{b}\end{array}$ & $\begin{array}{c}f_{i k}^{a} \\
(\text { Marek a. } \\
\left.\text { Richter }{ }^{47}\right)^{c}\end{array}$ & $\begin{array}{c}f_{i k} k^{a} \\
\left(\operatorname{Marek}^{48}\right)^{d}\end{array}$ & $\begin{array}{l}f_{i k}{ }^{a} \\
\text { (Meas - } \\
\text { ures et } \\
\left.\text { al. }{ }^{49}\right)^{d}\end{array}$ & $\begin{array}{c}\mathbf{f}_{\mathbf{i k}}{ }^{a} \\
\text { (Kwong a. } \\
\text { Meas- } \\
\left.\text { ures }^{50}\right)^{d}\end{array}$ & $\begin{array}{c}f_{i k} a \\
\text { Hannaford } \\
\text { and } \\
\left.\text { Lowe }^{51}\right)^{d}\end{array}$ \\
\hline$a^{7} \mathrm{~S}-\mathrm{z}^{7} \mathrm{P}^{\circ}$ & $\begin{array}{l}4254.33 \\
4274.81 \\
4289.73\end{array}$ & $\begin{array}{l}0.106 \\
0.082 \\
0.059\end{array}$ & $\begin{array}{l}0.111 \\
0.0849 \\
0.0616\end{array}$ & $\begin{array}{l}0.111 \\
0.0841 \\
0.0646\end{array}$ & 0.110 & $\begin{array}{l}0.112 \\
0.0849 \\
0.0627\end{array}$ & 0.0633 & 0.110 \\
\hline$a^{7} S-y{ }^{7} P^{0}$ & $\begin{array}{l}3578.68 \\
3593.48 \\
3605.32\end{array}$ & $\begin{array}{l}0.34 \\
0.28 \\
0.21\end{array}$ & $\begin{array}{l}0.355 \\
0.271 \\
0.220\end{array}$ & $\begin{array}{l}0.402 \\
0.319 \\
0.244\end{array}$ & & & & \\
\hline
\end{tabular}

${ }^{a}$ Listed oscillator strengths have been derived from lifetime measurements.

${ }^{b}$ Level-crossing technique.

${ }^{\circ}$ Phase shift method.

¿Laser excitation technique.

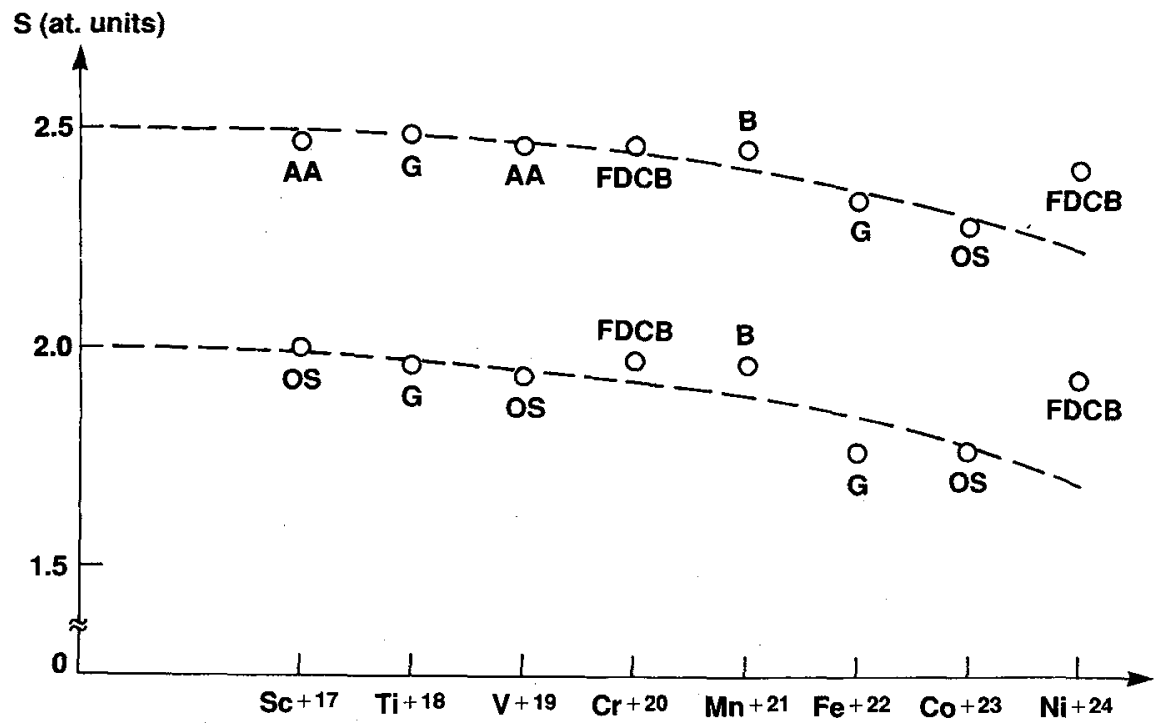

Fig. 5. Comparison of the line strengths (in atomic units) for two magnetic dipole ("forbidden") lines of $\mathrm{Be}$-like ions from $\mathrm{Sc}^{+17}$ to $\mathrm{Ni}^{+24}$. The points in the top row are for the $2 \mathrm{~s} 2 \mathrm{p}^{3} \mathrm{P}_{1}^{0}-{ }^{3} \mathrm{P}_{2}^{0}$ transition, while the lower row of the points is for the $2 \mathrm{~s} 2 \mathrm{p}^{3} \mathrm{P}_{0}-2 \mathrm{~s} 2 \mathrm{p}{ }^{3} \mathrm{P}_{1}$ transition. In pure LS-coupling, the two line strengths are 2.5 and 2.0 , respectively. The data sources (all theoretical) are: $\mathrm{AA}=$ Anderson and Anderson ${ }^{52} ; \mathrm{G}=$ Glass $^{54,57} ; \quad$ FDCB $=$ Feldman et al. ${ }^{55} ; \mathrm{B}$ $=$ Bhatia $^{56} ; \mathrm{OS}=$ Oboladze and Safranova ${ }^{53}$. 
4. Highly Stripped Ions--Magnetic Dipole Lines of Be-like Ions: Almost all data for highly-ionized atoms originate from various theoretical approaches, most often multiconfiguration self-consistent field approximations which include relativistic corrections to various degrees. These approaches have been effective in producing large numbers of data for many isoelectronic ions and readily show--for a given transition--the variation of the line strengths as a function of nuclear charge. Usually, only one or two comprehensive calculations are available for each spectrum and few data comparisons may be made. But for some magnetic dipole (M1) transitions of the beryllium isoelectronic sequence, data for the ions from $\mathrm{Sc}^{+17}$ to $\mathrm{Ni}^{+24}$ were contributed by six different sources $5-57$. We thus show in Figure 5 a graphical comparison of the material that was selected for these ions for the NIST compilations 25,26 . In the case of pure RussellSaunders coupling, the strengths of the two selected lines are 2.5 and 2 (in atomic units) and this has indeed been calculated for the lower ions of the Be-sequence (see Refs. 6 and 17). But due to increasing relativistic effects, including increased spin-orbit interaction, the line strengths gradually deviate from these numbers. All authors involved in the graphical comparison state that they have included relativistic effects, but few provide details of their calculations. Figure 4 shows increasing uncertainties in the general trend of these line strengths towards higher ions. As the broken line connecting the data indicates, we prefer the data by Glass 57 and Oboladze and Safranova ${ }^{3}$ for the most highly stripped ions, since the relativistic corrections applied by these authors are the most comprehensive ones.

5. Magnetic Dipole (M1) and Quadrupole (M2) Transitions for Helium-Like $T i, \mathrm{~V}$. $\mathrm{Cr}$ and Fe

Ions-A Rare Comparison Between Theory and Experiment: In this special instance both experimental ${ }^{58-51}$ and theoretical ${ }^{62}$ data are available for forbidden lines, the experimental data being supplied by lifetime measurements based on the beam-foil spectroscopy method. Table 4 shows the comparison between theory and the experiments. For the theory, the multi-configuration Dirac-Fock calculations by Hata and Grant ${ }^{62}$ have been selected for all ions of the Fe-group elements. The table shows that theory and experiment are always in complete agreement within the estimated error limits. With one exception (Ref. 60 for $\mathrm{Fe} X X V$ ), the agreement is within an impressive $\pm 5 \%$.

Table 4. Comparison of calculated and observed lifetimes (in ns) for the $2 \mathrm{~s}^{3} \mathrm{~S}_{1}$ state (M1 decay) and the $2 \mathrm{p}^{3} \mathrm{P}_{2}$ state (M2 + E1 decay) for several He-like ions.

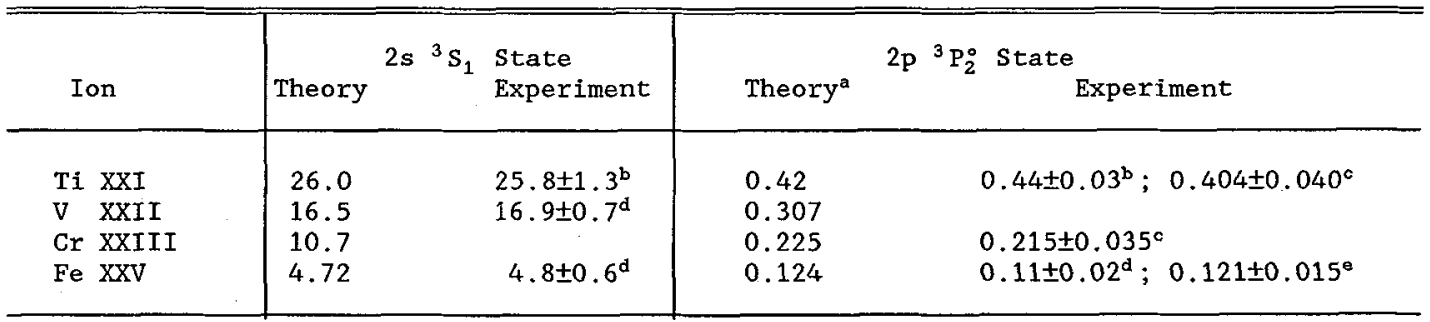

a The lifetime $r$ for this state is the reciprocal of the sum of the transition rates $2 p$ ${ }^{3} \mathrm{P}_{2}^{\circ}+1 \mathrm{~s}{ }^{1} \mathrm{~S}_{\circ}(\mathrm{M} 2)$ and $2 \mathrm{p}^{3} \mathrm{P}_{2}^{\circ} \rightarrow 2 \mathrm{~s}{ }^{3} \mathrm{~S}_{1}$ (E1), i.e., $\tau=[\mathrm{A}(\mathrm{M} 2)+\mathrm{A}(\mathrm{E} 1)]^{-1}$. The transition probability for the E1 transition $2 s^{\frac{1}{3}} \mathrm{~s}_{1}-2 \mathrm{p}^{3} \mathrm{P}_{2}^{\circ}$ is taken from the multi-configuration Dirac-Fock calculations of Hata and Grant, ${ }^{62}$
${ }^{b}$ Ref. 58
${ }^{d} \operatorname{Ref} .60$
${ }^{\circ}$ Ref. 59
${ }^{e} \operatorname{Ref} .61$

\section{F. Summary}

The critical compilation work of two atomic spectroscopy data centers at NIST has been briefly reviewed and a comprehensive list of current data tables has been provided. By discussing a recently published comprehensive tabulation of transition probabiities for Fegroup elements. in some detail, it is seen that many of these atomic data are still in need of improvement. Future work of the NIST spectroscopic data centers will concentrate on the spectra of lighter elements, in order to update and expand earlier data tables which are getting out of date. 


\section{$\underline{\text { References }}$}

1. C. E. Moore, Natl. Bur. Stds. (U.S.) Spec. Publ. 306, Sect 1 (1968); Sect. 2-4 (1969).

2. L. Hagan and W. G. Martin, Natl. Bur. Stds. (U.S.) Spec. Publ. 363 (1972); Suppl. 1(L. Hagan), 1977; Suppl. 2 (R. Zalubas and A. Albright), 1980; Supp1. 3 (A. Musgrove and R. Zalubas), 1985).

3. J. R. Fuhr, B, J. Miller, and G. A. Martin, Natl. Bur. Stds. (U.S.) Spec, Publ. 505 (1978); Suppl. 1 (1980).

4. I. Martinson, Rep. Prog. Phys. 52, 157 (1989).

5. C. E. Moore, Natl. Std. Ref. Data Ser.- Natl. Bur. Stds. (U.S.) 3, Sect. 6 (1972).

6. W. L. Wiese, M. W. Smith and B. M. Glennon, Natl. Std. Ref. Data Ser.- Natl. Bur. Stds. (U.S.) 4, (1966).

7. R. L. Kelly, J. Phys. Chem. Ref. Data 16, Suppl. 1 (1987).

8. J. Reader and C. H. Corliss, Eds., Handbook of Chemistry and Physics, 70th Ed., CRC Press, Boca Raton, Florida (1989).

9. A. R. Striganov and N.S. Sventitskii, Tables of Spectral Lines of Neutral and Ionized Atoms, IFI/Plenum Press, New York (1968).

10. W. C. Martin, J. Phys. Chem. Ref. Data 2, 257 (1973).

11. W. C. Martin, Phys. Rev. A36, 3575 (1987).

12. C. E. Moore, Natl. Std. Ref. Data Ser.- Natl. Bur. Stds. (U.S.) 35, Vol I-III (1971) (Reprint of NBS Circular 467, issued in 1949, 1952 and 1958).

13. C. E. Moore, Natl. Std. Ref. Data Ser. - Natl. Bur. Stds. (U.S.) $\underline{3}$, Sec. 3 (1970).

14. C. E. Moore, Nat1. Std. Ref. Data Ser.- Natl. Bur. Stds. (U.S.) $\underline{3}$, Sec. 4 (1972), and Sec. 5 (1975).

15. C. E. Moore, Natl. Std. Ref. Data Ser.- Natl. Bur. Stds. (U.S.) 3 , Sec. 7 (1976); Sec. 8 (1979); Sec. 9 (1980); Sec. 10 (1982); Sec. 11 (1985).

16. W. C. Martin and R. Zalubas, J. Phys. Chem. Ref. Data 10, 152 (1981).

17. W. L. Wiese, M. W. Smith and B. M. Miles, Natl. Std. Ref. Data Ser.- Natl. Bur. Stds. (U.S.) 22 (1969).

18. W. C. Martin and R. Zaluba, J Phys. Chem. Ref. Data 2, 1 (1980).

19. W. C. Martin and R. Zalubas, J. Phys. Chem. Ref. Data $\underline{8}, 817$ (1979).

20. W. C. Martin and R. Zalubas, J. Phys. Chem. Ref. Data 12,323 (1983).

21. W. C. Martin, R. Zalubas, and A. Musgrove, J. Phys. Chem. Ref. Data 14, 751 (1985).

22. W. C. Martin, R. Zalubas, and A. Musgrove, J. Phys. Chem. Ref. Data (in press).

23. J. Sugar and C. Corliss, J. Phys. Chem. Ref. Data 14, Suppl. 2 (1985).

24. V. Kaufman and J. Sugar, J. Phys. Chem. Ref. Data 17,1679 (1988).

25. G. A. Martin, J. R. Fuhr, and W. L. Wiese, J. Phys. Chem. Ref. Data 17, Suppl. 3 (1988).

26. J. R. Fuhr, G. A. Martin and W. I. Wiese, J. Phys. Chem. Ref. Data 17, Suppl, 4 (1988).

27. J. Sugar and A. Musgrove, J. Phys. Chem. Ref. Data (in press).

28. W. L. Wiese and G. A. Martin, Handbook of Chemistry and Physics, 70th Edition, CRC Press, Boca Raton, Florida (1989).

29. L. J. Curtis, in "Beam Foil Spectroscopy," Springer-Verlag, Berlin (1976).

30. W. L. Wiese, Chapter 25 in "Progress in Atomic Spectroscopy," Part B, W. Hanle and H. Kleinpoppen, Eds., Plenum Publ. Corp., New York (1979).

31. R. Wagner and E. W. Otten, Z Phys. 220, 349 (1969).

32. J. Z. Klose, Astrophys. J. 165,637 (1971).

33. R. C. Hilborn and R. de Zafra, Astrophys. J. 183,347 (1973).

34. J. Brzozowski, P. Erman, M. Lyyra, and w. H. Smith, Phys. Scr. 14, 48 (1976).

35. J. Marek, J. Richter and H. -J. Stahnke, Phys. Ser. 19, 325 (1979).

36. P. Hannaford and R. M. Lowe, J. Phys. B 14, L5 (1981).

37. G. D. Bell and E. F. Tubbs, Astrophys. J. 159, 1093 (1970).

38. J. M. Bridges and R. L. Kornblith, Astrophys. J. 192, 793 (1974).

39. D. E. Blackwell, P. A. Ibbetson, A. D. Petford, and M. J. Shallis, Mon. Not. R. Astron. Soc. 186, 633 (1979).

40. D. E. Blackwell, A. D. Petford, and M. J. Shallis, Mon. Not. R. Astron. Soc $\underline{186}, 657$ (1979).

41. M. May, J. Richter, and J. Wichelmann, Astron. Astrophys., Suppl. Ser. 18, 405 (1974).

42. J. Moity, Astron. Astrophys., Suppl. Ser. 52, 37 (1983).

43. R. L. Kurucz, Smithson. Astrophys. Observ. Spec. Rept. 390 (1981).

44. S. Johansson, Phys. Scr. 18, 217 (1978).

45. T. M. Bieniewski, Astrophys. J. 208, 228 (1976).

46. U. Becker, H. Bucka, and A. Schmidt, Astron. Astrophys, 59, 1 (1977).

47. J. Marek and J. Richter, Astron. Astrophys. 26, 155 (1973). 
48. J. Marek, Astron. Astrophys. 44,69 (1975).

49. R. M. Measures, N. Drewell, and H. S. Kwong, Phys. Rev. A 16, 10 (1977).

50. H. S. Kwong and R. M. Measures, Appl. Opt. 19, 1025 (1980).

51. P. Hannaford and R. M. Lowe, J. Phys. B 14, L5 (1981).

52. E. K. Anderson and E. M. Anderson, Opt. Spectrosc. (USSR) 52, 478 (1982).

53. N. S. Oboladze and U. I. Safranova, Opt. Spectrosc. (USSR) 48, 469 (1980).

54. R. Glass, Z. Phys. A 320,545 (1985).

55. J. Feldman, G. A. Doschek, Ch.-Ch. Chang, and A. K. Bhatia, J. App1. Phys. 51, 190 (1980).

56. A. K. Bhatia, J. Appl. Phys. $\underline{53}, 59$ (1982).

57. R. Glass, Astrophys. Space Sci. 91, 417 (1983).

58. H. Gould, R. Marrus, and R. W. Schmieder, Phys. Rev. Lett. 31,504 (1973) and unpublished results.

59. H. D. Dohmann, R. Mann, and E. Pfeng, Z. Phys. A. $\underline{309}, 101$ (1982):

60. H. Gould, R. Marrus, and P. J. Mohr, Phys. Rev. Lett. 33,676 (1974).

61. J. P. Buchet, M. C. Buchet-Poulizac, A. Denis, J. Desesquelles, M. Druetta, J. P. Grandin, M. Huet, X. Husson, and D. Lecler, Phys. Rev. A $\underline{30}, 309$ (1984).

62. J. Hata and I. P. Grant. Mon. Not. R. Astron. Soc. 211,549 (1984).

63. J. Sugar and A. Musgrove, J. Phys. Chem. Ref. Data 17, 155 (1988).

64. W. C. Martin, R. Zalubas and L. Hagan, Natl. Std. Ref. Data Ser.-Natl. Bur. Stds. (U.S.) 60 (1978). 